\title{
PERENCANAAN SUMBER DAYA MANUSIA KESEHATAN (SDMK) PUSKESMAS DI KABUPATEN JEMBER
}

\author{
Rizkiy Shofiah ${ }^{1}$, Dewi Prihatini' ${ }^{2}$, Sebastiana Viphindrartin ${ }^{3}$ \\ Pascasarjana Ilmu Kesehatan Masyarakat1, Fakultas Ekonomi dan Bisnis ${ }^{2,3}$, \\ Universitas Jember, Jember
}

\begin{abstract}
Abstrak
Puskesmas merupakan ujung tombak dalam penyelenggaraan pelayanan kesehatan di Indonesia Puskesmas merupakan fasilitas tingkat pertama yang mengupayakan pelayanan promotif dan preventif untuk mencapai derajat kesehatan. Puskesmas wajib memiliki minimal 5 tenaga promotif dan preventif yaitu analis laboratorium, farmasi, gizi, kesehatan masyarakat, dan sanitasi. Ketersediaan Sumber Daya Manusia Kesehatan (SDMK) khususnya tenaga analis laboratorium, gizi, kesehatan masyarakat, dan sanitasi masih belum merata di Puskesmas Kabupaten Jember Propinsi Jawa Timur. Perencanaan SDMK hanya fokus pada tenaga medis. Penelitian ini merupakan penelitian eksploratif kualitatif yang bertujuan untuk menganalisis proses perencanaan SDMK, khususnya tenaga promotif dan preventif, di Puskesmas di Jember. Informan penelitian adalah kepala tata usaha (bagian kepegawaian) dan analis laboratorium, gizi, kesehatan masyarakat, dan sanitasi. Hasil penelitian menunjukkan bahwa Puskesmas tidak memiliki tim khusus perencanaan SDMK dan masih membutuhkan tenaga analis, gizi, dan sanitasi. Puskesmas hanya melakukan analisis kebutuhan SDMK dan selanjutnya diajukan ke Dinas Kesehatan. Puskesmas tidak bisa melakukan perekrutan sendiri karena keterbatasan anggaran. Hal tersebut merupakan salah satu kendala yang menghambat dalam perencanaan SDMK. Kendala lainnya adalah Puskesmas haru menunggu keputusan dari Dinas Kesehatan dalam pemenuhan kebutuhan SDMK dengan penggunaan metode peramalan kebutuhan yang belum jelas sehingga akan menyebabkan adanya perbedaan persepsi diantara pengambil kebijakan.
\end{abstract}

Kata Kunci : $\quad$ perencanaan SDMK, preventif, promotif, Puskesmas.

\begin{abstract}
The public health center in Indonesia or known as Puskesmas has an important role in delivering health services. Puskesmas is a first-level facility delivering promotive and preventive health services. It must at least have 5 promotive and preventive personnel namely analysts of laboratory, pharmacy, nutrition, public health, and sanitation. The Health Human Resources/HRH, especially analysts of laboratory, nutrition, public health, and sanitation, distributed unequally in Puskesmas in Jember. Current HRH planning focuses only on medical personnel. Therefore, this study aims to analyze the HRH planning process, especially for the promotive and preventive personnel, in the Puskesmas in Jember. This is an exploratory study with a qualitative approach. The informants are head of the administration (HR department) and analysts of nutrition, public health, and sanitation. Results showed that Puskesmas did not have a special team for HRH planning. Some analysts, such as for nutrition and sanitation, are in urgent need. Puskesmas only analyzes HRH needs and then submits the results to the Health Department. They cannot do recruitment themselves due to budget constraints. This condition inhibits the HRH planning process as the Puskesmas must follow all decisions from the Health Department while the $H R$ forecasting method used is still unclear.
\end{abstract}

Keywords :

HRH planning, preventive, promotive, public health centre.

Universitas Jember

Jl. Kalimantan No. 37 Tegal Boto Jember

E-mail: rizkiyshofiah704@gmail.com 


\section{Pendahuluan}

Penyelenggaraan Sistem Kesehatan Nasional (SKN) menyataka bahwa sub sistem Sumber Daya Manusia Kesehatan (SDMK) sebagai pelaksana dalam upaya kesehatan perlu mencukupi jumlah, jenis, dan kualitas, serta distribusi secara adil dan merata sesuai kebutuhan dari pembangunan kesehatan (Perpres RI, 2012). SDMK salah satu bagian penting dalam upaya peningkatan kesejahteraan dan kesehatan masyarakat di Indonesia. SDMK merupakan ujung tombak pelayanan kesehatan di lapangan, baik secara preventif, promotif, kuratif, dan rehabilitatif. SDMK juga merupakan salah satu unsur utama peningkatan daya saing pelayanan kesehatan, serta tulang punggung upaya pelayanan kesehatan menghadapi peningkatan jumlah dan proporsi penduduk usia produktif dan lanjut usia di masa mendatang (Putri, 2017). Menurut Undang - Undang nomor 36 tahun 2014 tentang tenaga kesehatan menyatakan bahwa tenaga kesehatan merupakan bagian dari SDMK. Tenaga tersebut terdiri dari tenaga medis, tenaga psikologi klinis, tenaga keperawatan, tenaga kebidanan, tenaga kefarmasiaan, tenaga kesehatan masyarakat, tenaga kesehatan lingkungan, tenaga gizi, tenaga keterapian fisik, tenaga keteknisian medis, tenaga biomedika, tenaga kesehatan tradisional dan tenaga kesehatan lainnya (Permenkes, 2014).

Pusat kesehatan masyarakat (Puskesmas) merupakan ujung tombak penyelenggaraan pelayanan kesehatan di Indonesia. Puskesmas merupakan fasilitas pelayanan kesehatan yang menyelenggarakan upaya kesehatan masyarakat dan upaya kesehatan perseorangan pada tingkat pertama, dengan lebih mengutamakan upaya promotif dan preventif untuk mencapai derajat kesehatan masyarakat di wilayah kerjanya (Permenkes No. 75, 2014). Rencana Pembangunan Jangka Menengah Nasional (RPJMN) 2015 - 2019 dalam mendukung terwujudnya program Indonesia Sehat dan Germas, serta merupakan gambaran terpenuhinya tenaga kesehatan khususnya tenaga kesehatan promotive dan preventif dalam rangka memperkuat pelayanan kesehatan. Tenaga tersebut yaitu analis kesehatan, gizi, kesehatan masyarakat, sanitasi, dan kefarmasian (Peraturan Menteri Kesehatan No 75 tahun 2014).

Penyelenggaraan pelayanan kesehatan di Puskesmas harus didukung oleh tenaga kesehatan yang memadai guna menunjang fungsi puskesmas. Tahun 2017, masih terdapat banyak puskesmas yang mengalami kekurangan tenaga kesehatan, yaitu $25,14 \%$ puskesmas kekurangan dokter umum, 42,78\% kekurangan dokter gigi, 20,30\% kekurangan perawat dan 13,92\% puskesmas kekurangan bidan (Kemenkes, 2018). Dalam rencana aksi program badan pengembangan dan pemberdayaan sumber daya manusia kesehatan 2015 - 2019, menyebutkan untuk diadakan peningkatan sosialisasi dan advokasi dari Kementerian Kesehatan pada Pemerintah Daerah untuk menambah formasi dan rekrutmen tenaga kesehatan khususnya tenaga kesehatan masyarakat, sanitasi, analis kesehatan, dan tenaga gizi (PPSDM Kesehatan, 2015).

Kabupaten Jember merupakan salah satu kabupaten di Jawa Timur yang memiliki Puskesmas sejumlah 50 unit. Data Dinas Kesehatan tahun 2016 menunjukkan total SDMK Kabupaten Jember sebesar 2.937 yang terdistribusi sebanyak $54,31 \%$ atau sebanyak 1.595 orang tersebar di Puskesmas dan sebanyak $45,69 \%$ atau sebanyak 1.342 orang tersebar di rumah sakit yang ada di Kabupaten Jember. Rasio tenaga kesehatan terutama preventif dan promotif puskesmas belum mencapai target seperti tertuang dalam Kemenko Kesra No. 54 tahun 2013. Distribusi tenaga kesehatan yang belum merata akan berdampak pada pelayanan kesehatan menjadi tidak optimal. Perencanaan SDMK di Kabupaten Jember masih fokus untuk pemenuhan pada tenaga dokter, perawat, dan bidan, sedangkan untuk tenaga preventif dan promotif kurang mendapat perhatian. Dari 50 puskesmas di Kabupaten Jember 28 puskesmas belum memiliki tenaga gizi, 36 puskesmas belum memiliki tenaga sanitasi, 37 puskesmas belum memiliki tenaga kesehatan masyarakat, dan 30 puskesmas belum memiliki tenaga analis laboratorium (Dinas Kesehatan Jember, 2018).

Fenomena atau permasalahan yang terjadi yaitu peningkatan beban kerja di puskesmas 
semakin tinggi akan tetapi kebutuhan masyarakat terhadap pelayanan kesehatan juga meningkat. Keterbatasan SDMK karena tidak terdistribusi secara merata ini akan mempengaruhi pelayanan yang diberikan kepada masyarakat (Maria, 2017). Hal tersebut tentu berakibat kepada masyarakat yang menerima pelayanan kesehatan tidak maksimal karena keterbatas SDMK (Lestari, 2014). Penelitian ini bertujuan untuk mengetahui proses perencanaan tenaga promotif dan preventif puskesmas dengan peramalan kebutuhan menggunakan metode ABK Kesehatan sesuai Permenkes No 33 tahun 2015 tentang Pedoman Penyusunan Perencanaan Kebutuhan Sumber Daya Manusia Kesehatan.

\section{Metodologi}

\section{Jenis Penelitian}

Penelitian ini merupakan jenis penelitian kuantitatif dan kualitatif (mix method). Tahap pertama merupakan penelitian kuantitatif menggunakan metode Analisis Beban Kerja (ABK) Kesehatan. Tahap kedua merupakan penelitian kualitatif dengan pendekatan fenomenologi. Pendekatan ini digunakan untuk mengkaji dan membahas gambaran proses analisis kebutuhan dan perencanaan SDMK Puskesmas di Kabupaten Jember.

\section{Lokasi penelitian}

Penelitian ini dilakukan pada bulan Maret April 2019 pada hari kerja. Lokasi penelitian yaitu tiga kategori puskesmas di Kabupaten Jember berdasarkan Permenkes No. 75 tahun 2014. Puskesmas tersebut yaitu Puskesmas Silo 2 (pedesaan), Puskesmas Puger (pesisir), dan Puskesmas Sumbersari (perkotaan).

\section{Sumber dan analisis data}

Pada tahap pertama penelitian sumber data primer dalam penelitian ini diperoleh dari responden penelitian berupa data jumlah SDMK dilokasi penelitian, job desk, waktu kerja tersedia. Data primer digunakan untuk menghitung kebutuhan SDMK menggunakan metode ABK kesehatan melalui kegiatan pokok dan kegiatan penunjang yang dilakukan oleh masing - masing tenaga analis, gizi, kesehatan masyarakat, dan sanitasi di ketiga puskesmas tersebut. Data sekunder berupa jumlah SDMK di seluruh Puskesmas Kabupaten Jember yang diperoleh dari Dinas Kesehatan.

Teknik analisis data yang digunakan pada metode ABK yaitu dengan menetapkan fasilitas kesehatan (puskesmas) dan jenis SDMK, menetapkan waktu kerja tersedia, menetapkan komponen beban kerja dan norma waktu yang dibutuhkan, menghitung standar beban kerja, menghitung standar tugas penunjang dan faktor tugas penunjang, dan menghitung total kebutuhan SDMK.

Tahap kedua dengan pendekatan kualitatif dengan melakukan indepth interview dengan informan utama yaitu kepala tata usaha puskesmas selaku bagian kepegawaian tentang bagaimana proses atau tahapan perencanaan pemenuhan kebutuhan SDMK puskesmas dan kendala yang mungkin terjadi. Informan tambahan dalam penelitian ini yaitu tenaga analis, gizi, kesehatan masyarakat, dan sanitasi untuk mengetahui penyebab keterbatasan tenaga promotif dan preventif di Puskesmas Kabupaten Jember.

\section{Hasil dan Pembahasan}

Dalam melakukan analisis beban kerja kesehatan langkah pertama yang harus dilakukan yaitu menentukan jenis fasilitas kesehatan yaitu puskesmas. Selanjutnya waktu tersedia dalam satu tahun yaitu selama $1.200 \mathrm{jam} /$ tahun atau $72.000 \mathrm{menit} / \mathrm{tahun}$, dengan jumlah hari selama 312 hari/tahun karena puskesmas 6 hari kerja.

Hasil analisis kebutuhan SDMK dengan metode ABK Kesehatan yang dilakukan pada tiga puskesmas di Kabupaten Jember dengan karakteristik wilayah yang berbeda, yaitu pedesaa, pesisir, dan perkotaan. Hasil analisis tersebut menunjukkan bahwa setiap wilayah puskesmas mempunyai beban kerja yang berbeda. Berikut ini merupakan kebutuhan SDMK (Tenaga analis, gizi, kesehatan masyarakat, dan sanitasi) pada ketiga puskesmas tersebut. 
Puskesmas Silo 2 (Pedesaan)

Tabel 1. Kebutuhan SDMK Promotif dan Preventif Puskesmas Silo 2

\begin{tabular}{lcc}
\hline Jenis tenaga & $\begin{array}{c}\text { Jumlah } \\
\text { tenaga yang } \\
\text { ada }\end{array}$ & $\begin{array}{c}\text { Kebutuhan } \\
\text { sesuai ABK } \\
\text { Kes }\end{array}$ \\
\hline Analis & 1 & 2 \\
Gizi & 1 & 1 \\
Kesehatan & 1 & 1 \\
masyarakat & - & 0,30 \\
Sanitasi & -
\end{tabular}

Sumber : Puskesmas Silo 2, 2019

Tabel 1 merupakan gambaran hasil analisis kebutuhan SDMK promotif dan preventif dengan metode ABK Kes di puskesmas Silo 2. Puskesmas Silo 2 merupakan puskesmas rawat inap di daerah pedesaan dengan jumlah penduduk yang padat dibandingkan puskesmas pedesaan lainnya. Hasil analisis kebutuhan SDMK dengan metode ABK Kes menunjukkan puskesmas membutuhkan satu tambahan tenaga analis tambahan. Keterbatasan tenaga sanitasi menyebabkan adanya kerja ganda pada tenaga kesehatan. Hal tersebut karena tanggung jawab sebagai pelaksana sanitasi dilakukan oleh seorang perawat wilayah, sehingga pelayanan klinik sanitasi tidak berjalan maksimal.

Puskesmas Puger (Pesisir)

Tabel 2. Kebutuhan SDMK Promotif dan Preventif Puskesmas Puger

\begin{tabular}{lcc}
\hline Jenis tenaga & $\begin{array}{c}\text { Jumlah } \\
\text { tenaga yang } \\
\text { ada }\end{array}$ & $\begin{array}{c}\text { Kebutuhan } \\
\text { sesuai ABK } \\
\text { Kes }\end{array}$ \\
\hline Analis & 2 & 3 \\
Gizi & - & 0,24 \\
Kesehatan & 1 & 0,19 \\
masyarakat & & 2 \\
\hline Sanitasi & 1 & \\
\hline
\end{tabular}

Sumber : Puskesmas Puger, 2019

Tabel 2 merupakan gambaran hasil analisis kebutuhan SDMK promotif dan preventif dengan metode ABK Kes di Puskesmas Puger. Hasil analisis dengan metode ABK Kes menunjukkan puskesmas Puger membutuhkan satu tenaga analis dan sanitasi. Puskesmas Puger merupakan puskesmas di daerah pesisir yang memiliki karakter berbeda dengan wilayah pedesaan dan perkotaan. Data terkait beban kerja menunjukkan bahwa jenis pelayanan analis yang dilakukan di puskesmas puger lebih kompleks. Hal tersebut menyesuaikan dengan karakteristik wilayah dan masalah kesehatan yang ada di masyarakat.

Hasil wawancara dengan informan juga menyatakan bahwa tugas tenaga analis di Puskesmas Puger idealnya dilaksanakan oleh tiga orang. Namun, karena keterbatasan tenaga analis, kurangnya minat untuk bekerja di puskesmas, dan belum adanya tambahan tenaga dari Dinas Kesehatan menjadi penghambat dalam pemenuhan kebutuhan SDMK tersebut. Ketersediaan tenaga analis sangat dibutuhkan di puskesmas, mengingat puskesmas merupakan fasilitas tingkat pertama untuk pelayanan kesehatan di masyarakat. Hal tersebut dijelaskan dalam Permenkes No 37 tahun 2012 bahwa puskesmas perlu dilengkapi dengan laboratorium. Ada beberapa jenis pelayanan kesehatan di Puskesmas Puger yang membutuhkan kolaborasi dengan tenaga analis seperti pelayanan kehamilan, rawat jalan, rawat inap, pemeriksaan IMS rutin, dan saat melakukan pemeriksaan keliling.

Kebutuhan tenaga promotif dan preventif puskesmas tidak hanya pada tenaga analis, tapi juga tenaga gizi. Keterbatasan tenaga sanitasi menyebabkan terjadinya kerja ganda pada tenaga kesehatan. Hal tersebut karena tanggung jawab sebagai pelaksana gizi dilakukan oleh seorang bidan. Penelitian terkait beban kerja dan kinerja menjelaskan bahwa beban kerja memiliki dampak yang signifikan terhadap kinerja (Shah et al., 2014), artinya beban kerja pada pegawai harus sesuai kemampuan dan potensi yang dimiliki. Menurut Prasista et al (2017) rangkap jabatan dapat menimbulkan hambatan dalam kinerja karyawan. Kerja ganda sering terjadi pada tenaga kesehatan puskesmas yang diakibatkan oleh terbatasnya petugas yang ada. Hal tersebut akan berdampak pada pelayanan yang tidak maksimal, namun pengalaman kerja mempengaruhi signifikan terhadap kinerja pegawai. Hal tersebut dijelaskan oleh Rahmawati (2016) bahwa masa kerja membuat tugas yang berat menjadi lebih ringan dalam pelaksanaannya walau tidak maksimal seperti yang diharapkan. 
Puskesmas Sumbersari (perkotaan)

Tabel 3. Kebutuhan SDMK Promotif dan Preventif Puskesmas Sumbersari

\begin{tabular}{lcc}
\hline Jenis tenaga & $\begin{array}{c}\text { Jumlah tenaga } \\
\text { yang ada }\end{array}$ & $\begin{array}{c}\text { Kebutuhan } \\
\text { sesuai ABK Kes }\end{array}$ \\
\hline Analis & - & 2 \\
\hline Gizi & 1 & 1 \\
\hline $\begin{array}{l}\text { Kesehatan } \\
\text { masyarakat }\end{array}$ & 2 & 0,0225 \\
\hline Sanitasi & 1 & 0,26 \\
\hline
\end{tabular}

Sumber: Puskesmas Sumbersari, 2019

Tabel 3 merupakan gambaran hasil analisis kebutuhan SDMK promotif dan preventif dengan metode ABK Kes di puskesmas Sumbersari. Hasil analisis tersebut menunjukkan bahwa Puskesmas Sumbersari membutuhkan tenaga analis dan gizi seperti kedua puskesmas sebelumnya. Sebagai puskesmas di daerah perkotaan dimana pelayanan analis di Puskesmas Sumbersari tidak bervariasi seperti Puskesmas Puger karena di wilayah kota ada pelayanan laboratorium swasta. Namun, karena kepadatan jumlah penduduk atau sasaran puskesmas menyebabkan kebutuhan tenaga analis berdasarkan beban kerja juga meningkat.

Puskesmas Sumbersari merupakan puskesmas rawat inap yang memiliki satu petugas gizi. Menurut standar dalam Permenkes No 75 tentang puskesmas menyatakan bahwa idealnya puskesmas rawat inap memiliki dua tenaga gizi, yaitu gizi klinik dan gizi masyarakat. Jumlah penduduk yang padat, menyebabkan pelayanan gizi juga harus dilaksanakan oleh bidan karena keterbatasan tenaga gizi.

\section{Perencanaan SDMK Puskesmas}

SDMK merupakan aset yang cukup vital, hal tersebut disebabkan oleh keberadaannya dalam organisasi tidak bisa digantikan oleh sumber daya lainnya. Walaupun teknologi modern sudah banyak digunakan, tanpa dukungan dari SDMK yang memiliki kemampuan profesional hal tersebut tidak akan bermakna (Yuniarsih dan Suwatno, 2011). Ketersediaan SDMK sangat mempengaruhi pembangunan kesehatan. Keterbatasan tenaga promotif dan preventif puskesmas di Kabupaten Jember tentu menyebabkan pelayanan kesehatan terutama dalam hal promotif dan preventif tidak maksimal. Selain itu, juga menyebabkan beban kerja meningkat bagi sebagian besar tenaga kesehatan lainnya dengan adanya kerja ganda.

Dalam sesi wawancara dengan informan dijelaskan bahwa seluruh puskesmas tidak memiliki petugas atau tim khusus untuk perencanaan SDMK. Selama ini kepegawaian puskesmas dilaksanakan oleh kepala TU yang berkoordinasi dengan kepala puskesmas. Sebagai pelaksana dalam pelayanan kesehatan tingkat pertama, puskesmas tidak hanya mengalami keterbatasan tenaga kesehatan, tapi juga untuk tenaga non kesehatan seperti staf TU atau staf administrasi lainnya. Keterbatasan tersebut menyebabkan tenaga kesehatan juga harus melaksanakan tugas sebagai staf administrasi. puskesmas ditengah keterbatasan SDMK. Setiap karyawan diharapkan mempunyai rencana kerja untuk masing - masing program (Benhard et al, 2015). Petugas atau tim bagian manajemen SDM memiliki konstribusi untuk suksesnya organisasi. Hal tersebut karena manajemen SDM menjadi kunci untuk meningkatnya kinerja organisasi dalam memastikan aktivitas SDM (Grace et al, 2014).

\section{Tahap Perencanaan SDMK Puskesmas}

Desentralisasi mulai diterapkan pada tahun 2001 di Indonesia dan membawa perubahan pada semua pembangunan termasuk sektor kesehatan. Peran dalam perencanaan SDMK dialihkan pada pemerintah daerah guna mencapai tujuan pembangunan kesehatanyang menyeluruh, terpadu, dan berkesinambungan. Namun, dengan adanya kebijakan tersebut justru menyebabkan tidak meratanya distribusi tenaga kesehatan di daerah. Hal tersebut seperti yang terjadi di Kabupaten Jember yang memiliki 50 puskesmas baik rawat inap dan non rawat inap, dengan keterbatasan tenaga yang dimiliki masing - masing puskesmas.

Perencanaan SDMK puskesmas di Kabupaten Jember secara umum memiliki alur atau proses yang sama. Puskesmas hanya melakukan analisa kebutuhan SDMK dengan metode kira - kira dan selanjutnya diajukan ke Dinas Kesehatan. Proses implementasi untuk memenuhi kebutuhan tenaga tersebut hanya 
bisa dilakukan oleh Dinas Kesehatan, dan puskesmas hanya bisa menunggu untuk pemenuhan tenaga yang dibutuhkan. Selama Dinas Kesehatan belum bisa memenuhi kebutuhan tenaga tersebut, maka puskesmas memaksimal dengan tenaga yang ada walaupun akan menyebabkan kerja ganda.

Hasil wawancara dengan informan juga menyatakan bahwa adanya kebijakan dari pemerintah daerah yang menyatakan jika puskesmas tidak diperkenankan melakukan rekrutan tenaga apapun di puskesmas semakin menghambat pemenuhan kebutuhan tenaga yang dibutuhkan puskesmas tersebut.

Secara garis besar dalam penyusunan kebutuhan SDMK, untuk pengadaan dilakukan berdasarkan usulan dari pihak puskesmas yang dikoordinasikan dengan Dinas Kesehatan. Selanjutnya Dinas Kesehatan mengusulkan ke Badan Kepegawaian Daerah. Hal tersebut seperti yang tercantum dalam Permenkes No 33 tahun 2015 tentang penyusunan perencanaan SDMK menyebutkan acuan dalam penyusunan perencanaan kebutuhan SDMK di tingkat institusi dilakukan secara berjenjang dengan pendekatan perencanaan dari bawah (bottom up planning). Guspianto (2011) menyatakan bahwa penyusunan rencana kebutuhan SDMK merupakan bagian dalam dokumen laporan dari kegiatan rutin tahunan Dinas Kesehatan. Perencanaan dan pengadaan pegawai dilakukan apabila ada posisi yang kosong atau pegawai yang berhenti (Rivai, 2009). Namun, di lingkungan puskesmas Kabupaten Jember proses untuk pengadaan pegawai tidak terlaksana sebagaimana seharusnya untuk memenuhi kebutuhan petugas promotif dan preventif puskesmas yang keberadaannya terbatas.

\section{Anggaran dalam Perencanaan}

Puskesmas merupakan Unit Pelaksana Teknik Dinas (UPTD) yang berada dibawah naungan Dinas Kesehatan. Hal tersebut menyebabkan pengelolaan keuangan puskesmas mengikuti rencana ketentuan pengelolaan negara pada umumnya. Dalam Peraturan Pemerintah (PP) RI Nomor 58 Tahun 2005 disebutkan bahwa dana yang ditarik dari masyarakat atas pelayanan yang telah diberikan tidak dapat dipakai langsung untuk kebutuhan operasional karena harus disetorkan terlebih dahulu ke kas daerah.

Pengelolaan anggaran yang dirasa kurang flesibel juga berdampak terhadap perencanaan pemenuhan kebutuhan SDMK puskesmas. Berdasarkan hasil wawancara dengan informan menyatakan bahwa seluruh puskesmas tidak memiliki anggaran untuk melakukan perencanaan ataupun untuk melakukan rekrutan guna memenuhi kebutuhan tenaga. Keterbatasan anggaran ini merupakan salah satu penghambat bagi puskesmas untuk memberdayakan diri.

\section{Kendala dalam Proses Perencanaan}

Terdapat beberapa kendala yang dialami puskesmas dalam proses perencanaan SDMK. Kendala tersebut tidak hanya saat proses perencanaan, tapi hingga proses implementasi dalam memenuhi kebutuhan SDMK. Dari hasil wawancara dengan informan menyatakan ada beberapa hal yang menjadi kendala, yang pertama keterbatasan kapasitas puskesmas dalam perencanaan SDMK. Posisi puskesmas sebagai pelaksana hanya bisa menerima dan melaksanakan kebijakan dari Dinkes atau pemerintah daerah, dalam hal ini termasuk kebijakan terbaru bahwa puskesmas dilarang melakukan rekrutan tenaga apapun.

Kendala kedua yaitu proses implementasi dari Dinas Kesehatan cukup lama. Setelah pihak puskesmas mengajukan kebutuhan SDMK, puskesmas hanya bisa menunggu hingga waktu yang tidak bisa ditentukan. Hal tersebut menyebabkan kekosongan pada tenaga promotif dan preventif atau tenaga lainnya kosong dalam waktu cukup lama. Kekosongan tersebut pada akhirnya dilaksanakan oleh tenaga yang ada dan menyebabkan kerja ganda. Kendala ketiga, anggaran untuk proses perencanaan dan untuk gaji karyawan atau tenaga kesehatan. Puskesmas tidak memiliki anggaran khusus untuk pelaksanaan rekrutan tenaga baru. Kendala keempat, metode untuk peramalan atau menganalisis kebutuhan SDMK puskesmas yang belum baku atau belum menyesuaikan dengan metode terbaru. Berdasarkan hasil wawancara dengan informan menyatakan jika metode yang digunakan seperti metode perkiraan. Dalam 
praktiknya puskesmas menggunakan metode perkiraan atau menunggu ada posisi kosong akan mengajukan kebutuhan pada Dinas Kesehatan. Selain itu, adanya posisi yang tidak terisi karena SDMK yang ada mempertimbangkan gaji yang akan diperoleh. Penelitian ini juga diperkuat oleh pendapat Notoatmodjo (2009) menjelaskan terkait pengadaan SDM dalam organisasi dimana organisasi tersebut membuat proyeksi kebutuhan SDM dalam waktu tertentu dan dilanjutkan dengan memenuhi lowongan atau posisi yang dibutuhkan.

Kurang komunikasi antara manajemen puskesmas dan manajemen Dinas Kesehatan dalam perencanaan SDMK akan menghambat proses pemenuhan kebutuhan SDMK di puskesmas. Hal tersebut tentu akan menimbulkan tidak adanya kesamaan persepsi antara pihak puskesmas, Dinas Kesehatan atau pihak pengambil kebijakan. Hasil penelitian Marlinda (2017) mengemukakan bahwa sistem perencanaan tidak berjalanan dengan baik karena kurang lengkapnya data yang tersedia atau metode yang kurang tepat, kurangnya sosialisasi dan informasi tentang kebijakan yang digunakan dalam perencanaan tenaga kesehatan, serta konsultasi dan koordinasi yang kurang baik. Tanpa manajemen SDM yang handal, pengelolaan, penggunaan, serta pemanfaatan sumber - sumber lainnya menjadi tidak berguna (Siagian, 2010).

Puskesmas masih belum mampu untuk memberdayakan lingkup organisasinya secara maksimal. Hal tersebut karena segala sesuatu termasuk perencanaan pemenuhan kebutuhan SDMK harus bergantung pada Dinas Kesehatan. Posisi puskesmas sebagai pelaksana tentu hanya bisa menerima advokasi dan kebijakan yang berlaku walaupun dengan kondisi SDMK yang terbatas atau cenderung kurang di sebagian besar puskesmas Kabupaten jember. Puskesmas akan mampu memberdayakan diri sendiri atau lingkup organisasinya hanya ketika menjadi puskesmas BLUD atau Badan Layanan Umum Daerah. Puskesmas sebagai pelaksana pelayanan kesehatan seharusnya ditempatkan SDMK dengan latar belakang pendidikan dan keterampilan yang sesuai untuk menunjang fungsi puskesmas (Handayani et al, 2010).

\section{Kesimpulan}

Hasil analisis kebutuhan SDMK pada puskesmas dengan metode ABK kes menunjukkan bahwa seluruh puskesmas masih kekurangan tenaga promotif dan preventif. Tenaga gizi dibutuhkan di puskesmas pesisir dan perkotaan. Sedangkan tenaga sanitasi masih dibutuhkan di puskesmas pedesaan dan pesisir. Hasil analisis dengan metode $A B K$ kes juga menunjukkan adanya perbedaan beban kerja antara puskesmas wilayah pedesaan, pesisir, dan perkotaan.

Demikian halnya dengan proses perencanaan puskesmas tidak memiliki tenaga atau tim khusus sebagai perencana dalam pemenuhan kebutuhan SDMK. Tahap - tahap dalam perencanaan SDMK puskesmas hanya menganalisis kebutuhan SDMK dan selanjutnya diajukan pada Dinas Kesehatan untuk menindak lanjutkan proses implementasi dari kebutuhan SDMK tersebut. Ada beberapa kendala yang menghambat proses perencanaan untuk memenuhi kebutuhan SDMK. Pertama, puskesmas tidak memiliki anggaran untuk mengadakan perencanaan pemenuhan kebutuhan SDMK di lingkup organisasinya. Kedua, puskesmas tidak memiliki kapasitas untuk melakukan rekrutan karena terikat oleh kebijakan yang ada. Ketiga, proses implementasi dari Dinas Kesehatan perlu waktu cukup lama, sehingga menyebabkan posisi tenaga kesehatan yang kosong harus dilaksanakan oleh tenaga lainnya. Keempat, metode yang digunakan dalam peramalan kebutuhan SDMK masih belum sesuai dengan metode yang berlaku saat ini.

\section{Saran}

Dari hasil penelitian yang dilaksanakan pada tiga puskesmas di Kabupaten Jember terkait perencanaan kebutuhan SDMK dengan metode ABK kesehatan, saran yang dapat diberikan kepada pihak puskesmas dan Dinas Kesehatan. Saran untuk puskesmas, yaitu melakukan analisis kebutuhan tenaga dengan metode yang telah tercantum dalam Permenkes No 33 tahun 2015. Saran untuk Dinas Kesehatan, pertama untuk 
melaksanakan implementasi pemenuhan kebutuhan SDMK puskesmas untuk kelancaran proses pelayanan kesehatan. Kedua, perlu dilakukan pelatihan manajemen puskesmas agar sistem manajemen SDMK lebih baik, dan agar tercipta koordinasi yang baik antara pihak puskesmas dan bagian SDK Dinas Kesehatan. Ketiga, mempertimbangkan tenaga kesehatan yang telah diajukan oleh puskesmas dan memberi surat keputusan supaya tenaga tersebut bisa mendapatkan haknya berupa jasa pelayanan dari JKN.

\section{Daftar Referensi}

Benhard R. L. Paruntu A. J. M. Rattu C. R. Tilaar. 2015. Human Resource Requirements Planning in Health Center Minahasa District. JIKMU. Vol. 5, No. 1, Januari 2015.

Grace A. Salamate, A.J.M. Rattu, J.N. Pangemanan. 2014. Analisis Perencanaan Sumber Daya Manusia Kesehatan di Dinas Kesehatan Kabupaten Minahasa Tenggara. JIKMU, Suplemen Vol. 4, No. 4, Oktober 2014.

Guspianto. 2011. Analisis Penyusunan Rencana Kebutuhan Sumber Daya Manusia (SDM) Kesehatan di Kabupaten Muaro Jambi. Prosiding Seminar Nasional Kesehatan, Jurusan Kesmas FKIK Unsoed.

Handayani L, Ma'ruf N, dan Sopacua E. 2010. Peran Tenaga Kesehatan sebagai Pelaksana Pelayanan Kesehatan Puskesmas. Buletin Penelitian Sistem Kesehatan - Vol. 13 No. 1 Januari 2010: 12-20.

Kementerian Kesehatan RI. 2018. Profil Kesehatan Indonesia Tahun 2017.

Lestari, AB. 2014. Pelaksanaan JKN oleh BPJS Kesehatan Bulan Januari 2014 Kesehatan. Semarang: Divisi Regional VI BPJS Kesehatan.

Maria. A. X. Egam, Adisti A. Rumayar, Chreisye K.F. Mandagi.2017. Analisis Penempatan Sumber Daya Manusia Kesehatan di Puskesmas Kolongan Kabupaten Minahasa Utara. Jurnal Fakultas Kesehatan Masyarakat Universitas Sam Ratulangi.

Marlinda, Pebriana. 2017. Analisis Perencanaan Kebutuhan Tenaga Dokter oleh Dinas Kesehatan Kota Pekanbaru. Jurnal Niara Vol 9 No 2 Januari 2017.

Notoatmojo, S. 2009. Pengembangan Sumber Daya Manusia. Jakarta: Rineka Cipta

Pemerintah Republik Indonesia. 2005. Peraturan Pemerintah Republik Indonesia Nomor 58 tahun 2005 tentang Pengelolaan Keuangan Daerah. Jakarta: Menteri Hukum dan HAM RI

Pemerintah Republik Indonesia. 2012. Peraturan Pemerintah Republik Indonesia Nomor 72 tahun 2012 tentang Sistem Kesehatan Nasional. Jakarta: Menteri Hukum dan HAM RI

Peraturan Presiden Nomor 72. 2012. Sistem Kesehatan Nasional (LembaranNegara Nomor 193 Tahun 2012). Jakarta: Presiden RI.

Permenkes RI No 37. 2012. Penyelenggaraan Laboratorium Pusat Kesehatan Masyarakat. Jakarta: Kementerian Kesehatan Republik Indonesia.

Permenkes RI No 75. 2014. Peraturan Menteri Kesehatan Nomor 75 tahun 2014 tentang Pusat Kesehatan Masyarakat. Jakarta: Kementerian Kesehatan Republik Indonesia.

Permenkes RI No 33. 2015. Penyusunan Perencanaan Kebutuhan Sumber Daya Manusia Kesehatan. Jakarta: Kementerian Kesehatan Republik Indonesia.

Prasista., B., A. Yuniarta G., A., dan Wahyuni, M., A. 2017. Analisis Efektifitas dan dampak rangkap jabatan dalam peningkatan kinerja organisasi PT. Harta Ajeg Lestari, di Kelurahan Banyuning Kecamatan Buleleng. Jurnal S1 Ak, Universitas Pendidikan Ganesha, 8(2):1-10.

Putri, Aragar. 2017. Kesiapan Sumber Daya Manusia Kesehatan dalam Menghadapi Masyarakat Ekonomi Asean (MEA). Jurnal Medicoeticolegal dan Manajemen Rumah Sakit, 6 (1): 55-60, Januari 2017

Rahmawati, N. 2016. Pengaruh Kompensasi dan Pengalaman Kerja Terhadap Kinerja Karyawan. Jurnal Ilmu dan Riset Manajemen, $5(4): 1-15$

Rivai, V dan Sagala, E.J. 2009. Manajemen Sumber Daya Manusia Untuk Perusahaan: Dari Teori ke Praktik. PT Rajagrafindo Persada. Jakarta.

Shah S. S. H. H., Jaffari A., Aziz J., Ejaz W., UlHaq I., \& Raza S.2014. Workload and Performance of employes. Interdisciplinary Journal of Contemporary Research in Business, 3. 256267.

Siagian P Sondang. 2010. Manajemen Sumber Daya Manusia. Jakarta: PT. Bumi Aksara cetakan ke 18

Yuniarsih, Tjuju, dan Suwatno. 2011. Manajemen Sumber Daya Manusia. Bandung: Alfabeta 